\title{
Differentiating hyperlactatemia type A from type B: How does the lactate/ pyruvate ratio help?
}

\author{
Sebastien Redant ${ }^{1}$, Hamda Hussein ${ }^{1}$, Aude Mugisha ${ }^{1}$, Rachid Attou ${ }^{1}$, \\ David De Bels ${ }^{1}$, Patrick M. Honore ${ }^{1}$, Corinne C. De Laet ${ }^{2}$ \\ 'Department of Intensive Care, Brugmann University Hospital, Université \\ Libre de Bruxelles (ULB), Brussels, Belgium; \\ ${ }^{2}$ Department of Metabolic Disease, Academic Children Hospital Queen Fabiola, University, Libre de Bruxelles \\ (ULB), Brussels, Belgium
}

Address for Correspondence: Prof. Patrick M. Honore, MD, PhD, FCCM, Professor of Medicine, Department of Intensive Care, Brugmann University Hospital, Université Libre de Bruxelles (ULB), Brussels, Belgium E-mail: Patrick.Honore@CHUBrugmann.be

\begin{tabular}{|l|}
\hline Access this article online \\
\hline $\begin{array}{l}\text { Website: } \\
\text { www.intern-med.com }\end{array}$ \\
\hline $\begin{array}{l}\text { DOI: } \\
\text { 10.2478/jim-2019-0010 }\end{array}$ \\
\hline Quick Response Code: \\
\hline \\
\\
\\
\\
\end{tabular}

Lactate concentration is frequently measured in shock and particularly in septic shock. ${ }^{[1]}$ Lactic acidosis is traditionally attributed to cellular hypoxia resulting from inadequate oxygen demand and delivery. ${ }^{[2]}$ The lactate concentration is the result of a balance between its production and its elimination. Usually, this concentration is less than $2 \mathrm{mmol} / \mathrm{l}$, while its daily production is estimated at $1500 \mathrm{mmol} /$ day. Physiologically, lactate is produced by muscles $(25 \%)$, skin $(25 \%)$, brain $(20 \%)$, red globules $(20 \%)$ and intestines (10\%). Lactate is eliminated by liver and kidneys. ${ }^{[3]}$

Lactate elevation in diabetic ketoacidosis was previously described as rare and was considered primarily related to hypovolemia, hypotension, and hyperventilation. ${ }^{[4]}$ Cox et al. reported in a ketoacidosis patient population, a $40 \%$ prevalence of lactate greater than 4 $\mathrm{mmol} / \mathrm{l}^{\left[{ }^{[5]}\right.}$ This elevation of lactate was not correlated with blood pressure, length of stay or patient mortality but with glucose. ${ }^{[5]}$

Lactate production obeys the following biochemical reaction:

Pyruvate $+\mathrm{NADH}+\mathrm{H}^{+} \leftrightarrow$ Lactate + $\mathrm{NAD}^{+}$

In normal conditions, this reaction produces lactate from pyruvate in a 10 to 1 ratio. Pyruvate is derived from glycolysis and is then used by mitochondria. When the glycolysis increases or when the phosphorylation in mitochondria is blocked, for example, because of hypoxia, cyanide intoxication or mitochondrial disease, the pyruvate accumulates and is then converted into lactate leading to a state of hyperlactatemia and acidosis. ${ }^{[3,6]}$

In 1976, Cohen and Woods separated hyperlactatemia into two types: hyperlactatemia type $A$, related to inadequate perfusion of oxygen tissues and hyperlactatemia type B, without evidence of tissue hypoxia. Among type B hyperlactatemia, there are B1 types related to a process of failure of clearance such as hepatic insufficiency; B2 related to drugs or toxins; $\mathrm{B} 3$ related to inborn errors of metabolism. ${ }^{[7]}$ The proposed way of differentiating hypoxic hyperlactatemia from hyperlactatemia resulting from an increase in glycolytic flux is the use of the lactate/ pyruvate ratio (L/P ratio). ${ }^{[3]}$ At equilibrium, the $\mathrm{L} / \mathrm{P}$ ratio corresponds to:

Lactate $/$ pyruvate $=K \times(\mathrm{NADH} / \mathrm{NAD})$ $\mathrm{x} \mathrm{H}^{+}$

$K$ is the dissociation constant. This formula shows us that a decrease in the NADH/ NAD ratio or a drop in cytosolic $\mathrm{pH}$ decreases the $\mathrm{L} / \mathrm{P}$ ratio. ${ }^{[3]}$ The $\mathrm{L} / \mathrm{P}$ ratio evolves in parallel with the cytosolic redox potential and represents the balance between anaerobic and aerobic metabolism of the body. The higher this ratio is, the more the oxidative metabolism is defective with an important mitochondrial dysfunction. ${ }^{[8]}$ On the other hand, in non-hypoxic circumstances, lactate elevation occurs without elevation of the $\mathrm{L} / \mathrm{P}$ ratio, which remains below 10 (Figure 1)..$^{[9]}$ 
This situation is not frequently found because there are limitations when using the $\mathrm{L} / \mathrm{P}$ ratio, the Redox potential can be altered by factors other than the inability to use oxygen:

The measurement of the $\mathrm{L} / \mathrm{P}$ ratio is a plasma measurement. It is not well established if the $\mathrm{L} / \mathrm{P}$ ratio is identical to the cytosolic and to the mitochondrial ratio. ${ }^{[8]}$ The measurement of pyruvate is complex and not used in routine. Pyruvate degrades rapidly, which can falsely raise the ratio. ${ }^{[3]}$

In acute ketoacidosis, very low $\mathrm{pH}$ can be observed..$^{[8]}$ The $\mathrm{L} / \mathrm{P}$ ratio is related to $\mathrm{pH}$. A $\mathrm{pH}$ drop of 0.3 units can double the value of the $\mathrm{L} / \mathrm{P}$ ratio. An $\mathrm{L} / \mathrm{P}$ ratio greater than 30 can be found following the only variation of the $\mathrm{pH} \cdot{ }^{[10]}$ The ratio of $\mathrm{L} / \mathrm{P}$ is then interesting when hyperlactatemia is observed to persist after $\mathrm{pH}$ normalization in order to distinguish hypovolemia with secondary hypoxia from another cause.

In sepsis, the $\mathrm{L} / \mathrm{P}$ ratio could be normal following an elevation of pyruvate converted to lactate with respect of the law mass action:

Sepsis may be accompanied by a dysfunction of pyruvate dehydrogenase, the enzyme that catalyzes the conversion of pyruvate to acetyl Co A, and allows pyruvate to enter the Citric Cycle. This phenomenon causes an accumulation of pyruvate and lactate with a normal $\mathrm{L} / \mathrm{P}$ ratio. ${ }^{[11]}$

The protein catabolism generates the release of amino acids. These amino acids are converted in pyruvate and lactate. ${ }^{[3]}$

Neuroendocrine and cardiovascular disorders induce a sustained secretion of adrenaline. These high concentrations stimulate muscle adrenergic receptors, resulting in hyperactivity of $\mathrm{Na}-\mathrm{K}$ ATPase and glycolysis with concomitant lactate secretion without the elevation of the $\mathrm{L} / \mathrm{P}$ ratio. ${ }^{[12]}$

Lactate clearance may decrease due to hepatic dysfunction. ${ }^{[1]}$ Lactate extraction is dependent on hepatic perfusion, which must be at least greater than $25 \%$ of the basal rate. Similarly, lactate uptake depends on the monocarboxylate transporter 1(MCT1) receptor, which is saturable. Lactate is then used by gluconeogenesis which is inhibited by acidosis $(\mathrm{pH}<7.10)$. These three factors are encountered in sepsis and may explain an elevation of lactate with a variable $\mathrm{L} / \mathrm{P}$ ratio (Figure 1 and 3).

The $\mathrm{L} / \mathrm{P}$ ratio should be interpreted with caution. The interest of the $\mathrm{L} / \mathrm{P}$ ratio is mainly to establish the prognosis. The persistence of hyperlactatemia with a high $\mathrm{L} / \mathrm{P}$ ratio during the first 24 hour of septic shock is associated with a risk of multi-organ failure and death, a sign of the importance of anaerobic metabolism and hypoxia in the

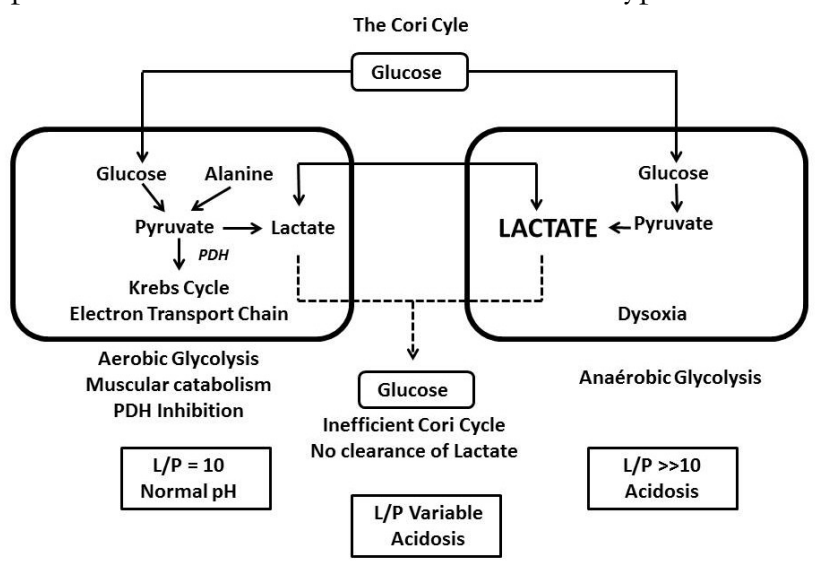

Figure 1: General scheme showing that in case of hypoxia, there is a hyperproduction of lactate with a significant increase in the $L / P$ ratio. In case of the other situation, the pyruvate is partially derived towards the Krebs cycle and the electron transport chain without increase in the $\mathrm{L} / \mathrm{P}$ ratio (Adapted with permission from reference from [17]).

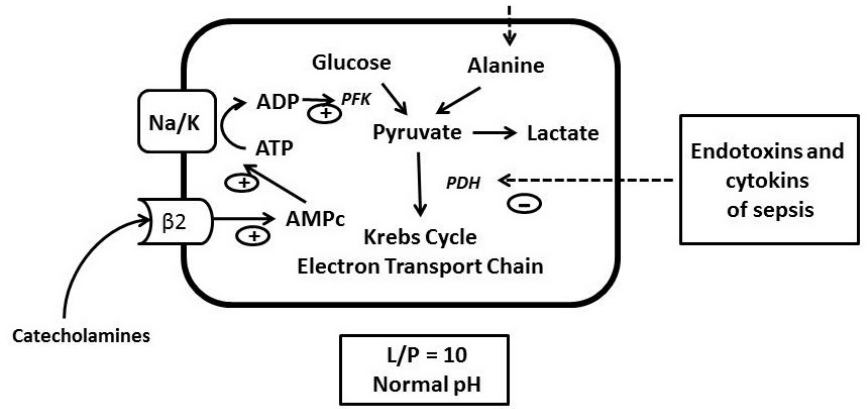

Figure 2: In case of sepsis, an inhibition of pyruvate dehydrogenase (PDH) by the endotoxins and cytokines of sepsis is observed. Following sepsis protein catabolism, there is an increase in alanine that will be converted to pyruvate. Sepsis is also accompanied by a hyperadrenergic state that via the $B 2$ receptor increases the conversion of ATP to ADP. The increase in ADP stimulates phosphofructokinase (PFK) and accelerates glycolysis (Adapted with permission from reference [17]).

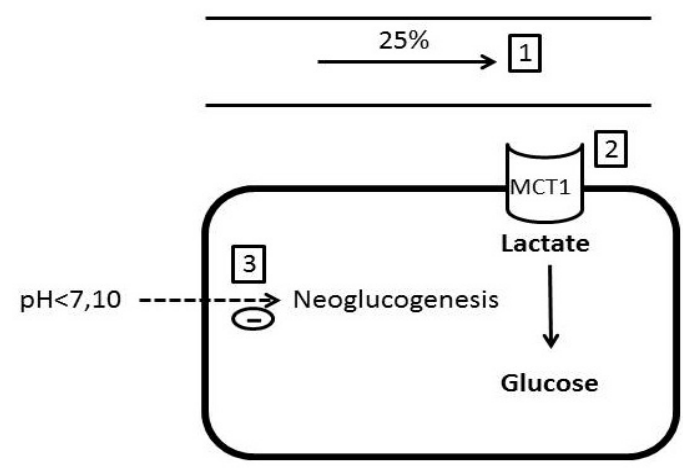

Figure 3: Lactate extraction is dependent on hepatic blood flow (1), availability of MCT1 receptors (2) and pH, which inhibits neoglucogenesis when it is below 7.10 (3) (Adapted with permission from reference [17]). 
onset of a pejorative evolution of the critical ill patient and, on the other hand, a deficiency of lactate clearance related to hepatic hypoperfusion, hepatocellular failure with impaired metabolism lactate and pyruvate by the liver related to the severity of shock and multiorgan failure. ${ }^{[13]}$ Likewise, an hyperlactatemia with a lower $\mathrm{L} / \mathrm{P}$ ratio (below 10) is a marker of good prognosis.

In conclusion, the $\mathrm{L} / \mathrm{P}$ ratio helps the clinician to better delineate the severity of hyperlactatemia when used together.

\section{Conflict of Interest}

The authors declare to have no competing interests

\section{REFERENCES}

1. Rusconi AM, Bossi I, Lampard JG, Szava-Kovats M, Bellone A, Lang E. Early goal-directed therapy in the treatment of severe sepsis and septic shock. N Engl J Med 2001; 345: 1368-77.

2. Suetrong B, Walley KR. Lactic acidosis in sepsis : It's not all anaerobic : implications for diagnosis and management. Chest 2016; 149: 252-61.

3. Levy B. Lactate and shock state: the metabolic view. Curr Opin Crit Care 2006; 12: 315-21.

4. Fulop M, Hoberman HD, Rascoff JH, Bonheim NA, Dreyer NP, Tannenbaum H. Lactic acidosis in diabetic patients. Arch Intern Med 1976; 136: 987-90.
5. Cox K, Cocchi MN, Salciccioli JD, Carney E, Howell M, Donnino MW. Prevalence and significance of lactic acidosis in diabetic ketoacidosis. J Crit Care 2012; 27: 132-7.

6. Alberti KG. The biochemical consequences of hypoxia. J Clin Pathol Suppl (R CollPathol) 1977; 11: 14-20.

7. Woods HF, Cohen RD. Clinical and biochemical aspects of lactic acidosis. Oxford, England : Blackwell Scientific; 1976: 1-20.

8. Leverve XM. From tissue perfusion to metabolic marker : assessing organ competition and co-operation in critically ill patients? Intensive Care Med 1999; 25: 942-8.

9. Hotchkiss RS, Karl IE. Reevaluation of the role of cellular hypoxia and bioenergetics failure in sepsis. JAMA 1992; $267: 1503-10$.

10. Cohen RD, Simpson. Lactate metabolism. Anesthesiology 1975; 43: 661-73.

11. Vary TC. Sepsis-induced alterations in pyruvate dehydrogenase complex activity in rat skeletal muscle: effects on plasma lactate. Shock 1996; 6: 89-94.

12. Levy B, Gibot S, Franck P, Cravoisy A, Bollaert PE. Relation between muscle $\mathrm{Na}+\mathrm{K}+\mathrm{ATPase}$ activity and raised lactate concentrations in septic shock : a prospective study. Lancet 2005; 365: 871-5.

13. Bakker J, Gris P, Coffernils M, Kahn RJ, Vincent JL. Serial blood lactate levels can predict the development of multiple organ failure following septic shock. Am J Surg 1996; 171: 221-6.

14. Chevrolet JC, Jolliet P. Le rôle du foie dans le metabolisme acido-basique. Med Hyg 1996; 54: 1840-9.

15. Halestrap AP, Wilson MC. The monocarboxylate transporter family-role and regulation. IUBMB Life 2012; 64: 109-19.

16. Mizock BA. Lactic acidosis. Dis Mon 1989; 35: 233-300.

17. Ben-Hamouda N, Haesler L, Liaudet L. Hyperlactatemia and lactic acidosis in the critically ill patient. Rev Med Suisse 2013; 9: 2335-40.

How to cite this article: Redant $\mathrm{S}$, Hussein $\mathrm{H}$, Mugisha A, Attou R, De Bels D, Honore PM, et al. Differentiating hyperlactatemia type A from type B: How does the lactate/pyruvate ratio help? J Transl Int Med 2019; 7: 43-5. 